\title{
Environmental policy of renewable energy industry under open conditions
}

\author{
Tian G. ${ }^{1, *}$ \\ ${ }^{1}$ School of Business, Pingxiang University, Pingxiang 337055, China \\ Received: 06/07/2020, Accepted: 04/08/2020, Available online: 22/10/2020 \\ *to whom all correspondence should be addressed: e-mail: 18663510797@163.com \\ https://doi.org/10.30955/gnj.003401
}

\section{Graphical abstract}

$$
\begin{aligned}
& \text { (i) } P^{\prime}(Q)<0 \\
& \text { (ii) } P^{\prime}(Q) \text { is fully bounded, to all } Q>0 \text {, there is }
\end{aligned}
$$

$$
P^{\prime \prime}(Q) Q+P^{\prime}(Q)<0
$$

\begin{abstract}
Renewable energy has two environmental externalities: one is the positive externality as an alternative to fossil energy consumption; the other is the negative externality with its production process consuming fossil energy. If the domestic renewable energy products export to foreign country with not only generating but importing renewable energy, what the environmental policy of both domestic and foreign governments should be? To this end, this paper establishes a renewable energy trade model of the two countries having only one firm for each other. Under the Cournot competition, the results show: first, if the two governments have no cooperation, the best environmental policy for domestic government would be taxation, but not necessarily the Pigouvian tax; foreign government not only impose on foreign manufacturer equal to pollution marginal damage, but also subsidize it over the marginal revenue of renewable energy; Second, if the two governments cooperate, the joint pollution tax is Pigouvian tax equal to the marginal damage of total pollution emissions, while joint subsidy is higher than the marginal revenue of total renewable energy.
\end{abstract}

Keywords: Environmental externality, renewable energy, Pigouvian tax, marginal pollution damage.

\section{Introduction}

Nowadays, the amount of pollutant emission in developed countries is much bigger than in developing countries, some developed countries have achieved the standards of greenhouse gas emission, in addition to domestic product and use of renewable energy sources, but also through the production of renewable energy in developing countries, not only satisfy the energy demand, but also achieve carbon dioxide reduction requirements. Taking the EU and South East Asian countries as an example, the EU has a sharp increment demanding for biofuels based on palm oil recently. To meet this demand, the EU carried out large amount of production of oil palm in Indonesia, Malaysia and other countries. However, due to the production of planting and produce of palm oil will emit a lot of carbon dioxide, leading to Indonesia being the biggest country of greenhouse gas emissions. Under this situation, how to make the renewable energy policy in developing countries and the developed countries has become the focus of this paper.

There are a large number of discussions about environmental policies in the past. Initially it is about the making of a government policy of a state under the closed condition, such as Pigou (1932), Buchanan (1969), etc. Baumol and Oates (1988) pointed out that under the fully competitive market, the levy rate is equal to the marginal damage to the pollution of the Pigou tax can rectify the externality of pollution, reaching Pareto optimality. However, when the market is not fully competitive, the conclusion above is generally no longer valid. Such as Buchanan (1969), Smith (1976), Barnett (1980), Misiolek (1988), Requate (2005), etc., they all pointed out that under the imperfectly competitive market, the optimal tax rate should be less than the marginal damage.

Along with the development of international trade, many documents begin to study the optimal environmental policy formulation under the opening conditions. Among which Conrad (1993), Copland (1994), Ulph (1996), Ulph (1997), Barret (1994), Farzin (2003), Dijkstra et al. (2011), Dong et al. (2012), Yang Yabo and Xu Shuying (2015) are some of the representative literatures. Conrad (1993) started to discuss how to replace industrial policy and trade policy with environmental policy. They point out that if the trade effect is considered, even under perfectly competitive market structure, the optimal pollution tax is no longer the Pigovian tax. Barret (1994) using the two countries competing model, in which the two countries believe that a country to develop a relaxed pollution emission standard is helpful to enhance the competitiveness of the country's manufacturers, but this initiative is not as effective as $R$ \& D subsidies and export subsidies. Ulph (1996) discuss whether trade liberalization will cause environmental damage. Dijkstra et al. (2011) 
found that the import of the Congress to develop a lower than the export tax rate of pollution in order to attract exporters to the importing country for direct investment (FDI). Dong et al. (2012) constructed a model of intra industry trade between North and South China to investigate the pollution discharge standards of the two countries. The paper finds that when the pollutants are regional pollution, the two government trend to become more stringent emission standards; but when pollutants are trans-boundary pollution, the two government trend to race to the bottom of pollution emission standard. Yang Yabo and Xu Shuying (2015) discussed the optimal environmental policy of the export country and the optimal tariff policy of the importing country, while the regional pollution and trans-boundary pollution were also discussed (Amina et al., 2019; Ibrahim et al., 2018; Most et al., 2019; Yasin et al., 2018).

We have found from reviewing many documents that we have been widely discussed for industrial and environmental policy and environmental policy under open general conditions of polluting industries. However, the literatures to explore renewable energy industry policy under the open condition are still rare. Brander \& Spencer (1985) and Eaton and Grossman (1986), Bernhofen (1997), Ishikawa \& Spencer (1999) and other classics of the international trade literature explores the general industry trade policies. However, there are many differences between renewable energy industry differ and general industry: it can not only replace the petrochemical energy more can reduce pollution emissions, but also the consumption of the environment has a positive externality. In addition, its production process also consumes the traditional energy, and produce pollution emission, which leads negative externalities (such as the production process of bio-energy, just the same). Therefore, when the government formulates the renewable energy policy, not only various economic tools are used to promote its production, but also pollution damage is restricted and limited to correct the market failure. Among the present literatures, the researches on the optimal environmental policy of renewable energy industry are not much (Dali et al., 2018; Mozina et al., 2018; Muhammad et al., 2020; Nur et al., 2020).

For this purpose, we extend the model which Requate (2005) sets, especially for the setting of the cost function, but the difference with this model is that the paper of Requate (2005) discussed the environmental policy of the general pollution industry, and the environmental policy of the renewable energy industry, which has two kinds of externalities. Beyond this, this paper set up a dynamic two stage game model of the two governments in the two countries, which assuming that there is Cournot quantity competition among the manufacturers, and to discuss how to formulate the optimal renewable energy policy for the renewable energy exporting countries (domestic) and the production and consumption country (foreign). It is found that whether the two companies have pollution prevention technology, renewable energy policy should tax, and foreign governments on the one hand to deal with foreign renewable energy companies to levy taxes, on the other hand, meanwhile responding to foreign renewable energy subsidies. These conclusions above are rarely mentioned in the literature before.

\section{Settings and descriptions of the basic model}

Assume that in the international economy system, the renewable energy industry is engaged only in domestic ( $h$ ) and foreign country ( $f$ ), there is one manufacture in each of the two countries, their renewable energy products will be exported to foreign countries, and making Cournot competition with foreign manufacturers in foreign markets.

Since the production of domestic manufacturers of renewable energy are exported to foreign markets rather than in the domestic market consumption, the country does not enjoy the positive impact brought about by the consumption of renewable energy, but must bear the pollution damage when renewable energy production, and therefore, their Government pollution tax $\left(t_{f}\right)$ levied on domestic firms without subsidies. Foreign government pollution $\operatorname{tax}\left(t_{f}\right)$ levied on foreign firms, meanwhile, due to the consumption of renewable energy in foreign, foreign environment has a positive effect, while giving it a foreign government subsidies to foreign firms. Social welfare is defined as the total surplus (consumer surplus + Profit) minus plus pollution social damage caused by external income energy consumption (defined below in detail) on regeneration. In this paper, $q_{i}, e_{i}$ indicate the renewable energy output and pollution emissions of manufacturer $i(i$ $=\mathrm{h}, \mathrm{f}$, similarly hereinafter). Total output $Q=q_{\mathrm{h}}+q_{\mathrm{f}}$, total pollution emissions $E=e_{\mathrm{h}}+e_{\mathrm{f}}$.

\subsection{Preference}

Social preference is expressed by anti demand function $P$ and social welfare loss function $D$. Let $P=P(Q)$ be the anti demand function, which meets two continuous differentiable, and:

(i) $P^{\prime}(Q)<0$;

(ii) $P^{\prime \prime}(Q)$ is fully bounded, to all $Q>0$, there is

$$
P^{\prime \prime}(Q) Q+P^{\prime}(Q)<0
$$

Formula 1 indicates that the anti demand function is not too convex, so that it can satisfy the two order condition of the maximum of manufacturers' profits and social welfare. Then let $D\left(e_{i}\right)$ be the function of welfare damage caused by pollution emission, which stratifies $D^{\prime}\left(e_{i}\right)>0, D^{\prime \prime}\left(e_{i}\right)>0$.

\subsection{Technology}

Manufacturers' production technology is expressed by the simplified cost function (which means all the elements of the market are fully competitive). For the convenience of analysis, we will discuss by ways of whether the manufacturer has pollution control technology.

\subsubsection{Manufacturers do not have pollution control technology}


If the manufacturers don't have pollution control technology, then the manufacturers only have production cost without pollution control cost.

1. The cost function of manufacturer $i$ is $C^{i}\left(q_{i}\right)$, and $C_{i}^{\prime}\left(q_{i}\right)>0, C_{i}^{\prime \prime}\left(q_{i}\right)=0$, that is to say that the marginal cost is a positive constant, let it be $\mathrm{MC}_{i}=\mathrm{C}_{i}$.

2. Assuming that the manufacturer produces 1 unit renewable energy requires $\delta_{i}$ units fossil energy, $0<\delta_{i}<1$, and 1 unit fossil energy input causes 1 unit pollution emission. So that manufacturers' pollution emissions be $e_{i}=\delta q_{i}$. The two manufacturers' profit function be:

$$
\begin{aligned}
& \pi_{h}=P(Q) q_{h}-C^{h}\left(q_{h}\right)-t_{h} e_{h} \\
& \pi_{f}=P(Q) q_{f}-C^{f}\left(q_{f}\right)-t_{f} e_{f}+s q_{f}
\end{aligned}
$$

In which $t_{i}, s$ represent pollution tax rate of the two governments and renewable energy subsidies for foreign governments respectively. Assuming that the use of renewable energy won't cause pollution emission, and there is external benefits caused by the replacement fossil energy to reduce pollution emission, let $B(Q)$ be the external benefits function caused by the use of renewable energy, and $B_{Q}>0, B_{Q Q}<0$. National welfare function $\left(W_{h}\right)$ and foreign welfare function $\left(W_{f}\right)$ can be expressed as:

$$
\begin{aligned}
& W_{h}=P(Q) q_{h}-C^{h}\left(q_{h}\right)-D\left(e_{h}\right) \\
& W_{f}=\int_{0}^{Q} P(x) d x-P(Q) q_{h}-C^{f}\left(q_{f}\right)+B(Q)-D\left(e_{f}\right)
\end{aligned}
$$

\subsubsection{Manufacturers have pollution control technology}

Manufacturers will carry out pollution control if they have pollution control technology. Then the manufacturers cost includes production costs and pollution control costs, let it be $C^{i}\left(q_{i}, e_{i}\right)$. We will make the following assumptions about this cost function:

i. The marginal production cost is a positive constant, that is to say $C_{q}\left(q_{i}, e_{i}\right)>0, C_{q q}\left(q_{i}, e_{i}\right)=0$ (omit subscript $i$ ), let it be $\mathrm{MC}_{i}=c_{i}$.

ii. The marginal cost of pollution is negative $\left(C_{e}^{i}\left(q_{i}, e_{i}\right)<0\right)$ and increase progressively $\left(C_{e e}^{i}\left(q_{i}, e_{i}\right)>0\right)$ on every fixed output level, that is to say the marginal pollution control cost is positive $\left(-C_{e}^{i}\left(q_{i}, e_{i}\right)>0\right)$ and increase progressively $\left(C_{e e}^{i}\left(q_{i}, e_{i}\right)>0\right)$.

iii. $\quad C_{q e}^{i}\left(q_{i}, e_{i}\right)=0$. This hypothesis indicates that the cost function is Separation additive.

The profit functions of the two manufacturers are:

$$
\begin{aligned}
& \pi_{h}=P(Q) q_{h}-C^{h}\left(q_{h}, e_{h}\right)-t_{h} e_{h} \\
& \pi_{f}=P(Q) q_{f}-C^{f}\left(q_{f}, e_{f}\right)-t_{f} e_{f}+s q_{f}
\end{aligned}
$$

National welfare function $\left(W_{h}\right)$ and foreign welfare function $\left(W_{f}\right)$ can be expressed as:

$$
\begin{aligned}
& W_{h}=P(Q) q_{h}-C^{h}\left(q_{h}, e_{h}\right)-D\left(e_{h}\right) \\
& W_{f}=\int_{0}^{Q} P(x) d x-P(Q) q_{h}-C^{f}\left(q_{f}, e_{f}\right)+B(Q)-D\left(e_{f}\right)
\end{aligned}
$$

There are two cases when solving this module, one is that when the two countries don't cooperate with each other and each of them pursue their own social welfare maximization, what is their respective optimal renewable energy policy; the other one is when they cooperate with each other, what is their optimal renewable energy policy when under the case of the pursuit of maximum joint benefits. For the two cases, we will set a two stage game respectively: first stage, the two countries need to make their own optimal pollution emission tax and renewable energy subsidies; second stage, under the specific renewable energy policy, the two manufactures carry out production and pollution prevention. In this paper, the reverse induction method is used to deal with the two stage game. Which means firstly you need to make the optimal decision with the specific policy and bring the decision into the government's social welfare function, to solve the government's optimal renewable energy policy. Next, we will discuss by way of whether the manufacture has pollution prevention technology.

\section{Solving the model (I): Manufacturers do not have pollution prevention technology}

\subsection{If the two governments do not cooperate with each other}

\subsubsection{Firstly we need to make the manufacturer's optimal decision in the second stage}

The first order partial derivative of the manufactures' profit function (2), (3) with respect to the production, and make it equals 0 , there is:

$$
\begin{aligned}
& \frac{\partial \pi_{h}}{\partial q_{h}}=P(Q)+P^{\prime}(Q) q_{h}-C_{q}^{h}\left(q_{h}\right)-t_{h} \delta_{h}=0 \\
& \frac{\partial \pi_{f}}{\partial q_{f}}=P(Q)+P^{\prime}(Q) q_{f}-C_{q}^{f}\left(q_{f}\right)+s-t_{f} \delta_{f}=0
\end{aligned}
$$

After processing the formula, there is:

$$
\begin{aligned}
& \underbrace{P(Q)+P^{\prime}(Q) q_{h}}_{M R_{h}}=C_{q}^{h}\left(q_{h}\right)+t_{h} \delta_{h} \\
& \underbrace{P(Q)+P^{\prime}(Q) q_{f}}_{M C_{h}}+s=\underbrace{C_{q}^{f}\left(q_{f}\right)}_{M R_{f}}+t_{f} \delta_{f}
\end{aligned}
$$

We can see from the formula (12) and (13) that, when producing renewable energy, the two manufacturers will be influenced by consumption price, production costs, fossil energy investment ratio, renewable energy subsidy rate and pollution emission rate, and the demand price elasticity the two manufactures face. Also the national manufacture will carry out production when the marginal revenue $\mathrm{MR}_{h}$ equals marginal production cost $\mathrm{MC}_{h}$ plus marginal cost of pollution $\left(t_{h} \delta_{h}\right)$; differently, foreign manufactures will carry out production when marginal 
revenue $\mathrm{MR}_{f}$ plus marginal subsidy $(s)$ equal marginal production cost $\mathrm{MC}_{f}$ plus marginal cost of pollution $\left(t_{f} \delta_{f}\right)$.

Furthermore, formula (12) and (13) implicit defined that the two countries' optimal renewable energy output (and pollution emissions) is the function of pollution tax rate $t_{h}$, $t_{f}$ and the subsidy rate $s$. For formula (12) and (13), make the partial derivative of $q_{h}, q_{f}, Q$ with respect to the pollution tax rate $t_{h}, t_{f}$ and the subsidy rate $s$, then we can get the influence of the two countries' pollution emission rate, net renewable energy subsidies to renewable energy production (and pollution emission ), there is:

$$
\begin{aligned}
& \frac{\partial q_{h}}{\partial t_{h}}=\frac{\delta_{h}\left(2 P^{\prime}+P^{\prime \prime} q_{f}\right)}{A}<0 \\
& \frac{\partial q_{f}}{\partial t_{h}}=-\frac{\delta_{h}\left(P^{\prime}+P^{\prime \prime} q_{f}\right)}{A}>0 \\
& \frac{\partial Q}{\partial t_{h}}=\frac{\partial q_{h}}{\partial t_{h}}+\frac{\partial q_{f}}{\partial t_{h}}=\frac{\delta_{h} P^{\prime}(Q)}{A}<0 \\
& \frac{\partial q_{h}}{\partial t_{f}}=-\frac{\delta_{f}\left(P^{\prime}+P^{\prime \prime} q_{h}\right)}{A}>0 \\
& \frac{\partial q_{f}}{\partial t_{f}}=\frac{\delta_{f}\left(2 P^{\prime}+P^{\prime \prime} q_{h}\right)}{A}<0 \\
& \frac{\partial Q}{\partial t_{f}}=\frac{\partial q_{h}}{\partial t_{f}}+\frac{\partial q_{f}}{\partial t_{f}}=\frac{\delta_{f} P^{\prime}(Q)}{A}<0 \\
& \frac{\partial q_{h}}{\partial s}=\frac{\left(P^{\prime}+P^{\prime \prime} q_{h}\right)}{A}<0 \\
& \frac{\partial q_{f}}{\partial s}=-\frac{\left(2 P^{\prime}+P^{\prime \prime} q_{h}\right)}{A}>0 \\
& \frac{\partial Q}{\partial s}=\frac{\partial q_{h}}{\partial s}+\frac{\partial q_{f}}{A}=-\frac{P^{\prime}(Q)}{A}>0 \\
& \frac{A}{A}
\end{aligned}
$$

where $A=\left(2 P^{\prime}+P^{\prime \prime} q_{h}\right)\left(2 P^{\prime}+P^{\prime \prime} q_{f}\right)-\left(P^{\prime}+P^{\prime \prime} q_{h}\right)\left(P^{\prime}+P^{\prime \prime} q_{f}\right)>0$. Formula (14)-(19) indicate that one government raises the pollution emission tax rate will increase the other country's renewable energy output, and decrease the production of tax state, which declined the market's total renewable energy yield. Formula (20)-(22) indicate that foreign country's increment of subsidy rate will decrease the national country's renewable energy yield, increase the foreign country's renewable energy yield, finally cause the increment of the total renewable energy.

\subsubsection{Then make the two governments' optimal renewable energy policy}

The two governments must make their own optimal renewable energy policy because they don't cooperate with each other. Make the first order partial derivative of the national social welfare function respectively:

$$
\begin{aligned}
& \frac{\partial W_{h}}{\partial t_{h}}=\left[P(Q)+P^{\prime}(Q) q_{h}-C_{q}^{h}\left(q_{h}\right)-\delta_{h} D^{\prime}\left(e_{h}\right)\right] \frac{\partial q_{h}}{\partial t_{h}} \\
& +P^{\prime}(Q) q_{h} \frac{\partial q_{f}}{\partial t_{h}}=0
\end{aligned}
$$

Bring (12), (14) and (15) into (23), we can get:

$$
t_{h}=D^{\prime}\left(e_{h}\right)+\frac{P^{\prime} q_{h}\left(P^{\prime}+P^{\prime \prime} q_{f}\right)}{\delta_{h}\left(2 P^{\prime}+P^{\prime \prime} q_{f}\right)}<D^{\prime}\left(e_{h}\right)
$$

That is to say, when the two governments don't cooperate, give the foreign government's pollution emission tax rate and renewable energy's subside rate, the optimal pollution discharge rate of the national government is less than the marginal damage of pollution. The economic intuition behind is that, on one side, to correct the market failure, the national pollution tax rate should be equal to the pollution marginal damage $D^{\prime}\left(e_{h}\right)$, however, on the other side, due to the export of renewable energy products abroad, and its oligopoly competition in foreign markets, thus in order to improve national manufactures' competition, making foreign profits, we should reduce national pollution tax rate (which means national government should give more subsidies on the basic of collecting pollution tax rate), consequently, the optimal pollution tax is less than the marginal damage of pollution.

In the same way, we can find out the optimal pollution emission tax rate of foreign government and the subsidy rate of net renewable energy:

$$
\begin{aligned}
& \frac{\partial W_{f}}{\partial t_{f}}=\left[P(Q)-P^{\prime}(Q) q_{h}-C_{q}^{f}\left(q_{f}\right)+B^{\prime}(Q)-\delta_{f} D^{\prime}\left(e_{f}\right)\right] \frac{\partial q_{f}}{\partial t_{f}} \\
& +\left(B^{\prime}-P^{\prime} q_{h}\right) \frac{\partial q_{h}}{\partial t_{f}}=0 \\
& \frac{\partial W_{f}}{\partial s}=\left[P(Q)-P^{\prime}(Q) q_{h}-C_{q}^{f}\left(q_{f}\right)+B^{\prime}(Q)-\delta_{f} D^{\prime}\left(e_{f}\right)\right] \frac{\partial q_{f}}{\partial s} \\
& +\left(B^{\prime}-P^{\prime} q_{h}\right) \frac{\partial q_{h}}{\partial s}=0
\end{aligned}
$$

The formula (13) which is the first order condition of the manufacturer's profit maximization is brought into the previous two formulas, and simplified formulas by using (17), (18), and has:

$$
t_{f} \delta_{f}-s=P^{\prime}(Q) Q-B^{\prime}(Q)+\delta_{f} D^{\prime}\left(e_{f}\right)-\left(B^{\prime}-P^{\prime} q_{h}\right) \frac{P^{\prime}+P^{\prime \prime} q_{h}}{2 P^{\prime}+P^{\prime \prime} q_{h}}
$$

To make the optimal pollution emission tax rate and the subsidy rate of net renewable energy:

$$
\begin{aligned}
& t_{f}=D^{\prime}\left(e_{f}\right) \\
& s=-P^{\prime}(Q) Q+B^{\prime}(Q)+\left(B^{\prime}-P^{\prime}(Q) q_{h}\right) \frac{P^{\prime}+P^{\prime \prime} q_{h}}{2 P^{\prime}+P^{\prime \prime} q_{h}}
\end{aligned}
$$

We can know that by formulas (28), (29), because we assume that foreign manufacturers is the exclusive manufacturers, on the one hand foreign governments will develop a higher subsidy rate to promote renewable energy output of foreign manufacturers; On the other hand, due to the competition's existence of domestic renewable energy products, foreign government will 
increase the subsidy rate to reduce the cost of manufacturers to improve the competitiveness of its domestic manufacturers, and therefore the foreign government will develop a higher renewable energy subsidies, so the optimal renewable energy subsidy rate is higher than the Pigou subsidies $B^{\prime}(Q)$. The optimal pollution emission tax rate of foreign governments is equal to the marginal damage of pollution $D^{\prime}\left(e_{f}\right)$, so the optimal pollution emission tax rate is the Pigou tax. From what has been discussed above, there are the following propositions.

Proposition 1: if the manufacturer does not have the pollution control technology, and the two governments do not cooperate, the optimal pollution emission tax rate is less than the marginal damage of pollution; foreign government's renewable energy subsidy rate is equal to the Pigou tax, but its renewable energy subsidies rate is higher than the marginal revenue of renewable energy.

\subsection{If the two governments cooperate}

\subsubsection{Seeking the manufacturer's optimal decision of the} second stage firstly

If the two governments cooperate, the two governments on the two sides of the two manufacturers of pollution emissions tax, the two governments will tax manufacturers of two sides for pollution emissions, and give net renewable energy subsidies to the manufacturers of two countries. Therefore, when the two governments develop renewable energy policy jointly, the two manufacturers profit function is:

$$
\pi_{i}=P(Q) q_{i}-C^{i}\left(q_{i}\right)-t \delta q_{i}+s q_{i}, i=h, f
$$

The first order conditions of profit maximization between the manufacturers of two countries:

$$
\frac{\partial \pi_{i}}{\partial q_{i}}=P(Q)+P^{\prime}(Q) q_{i}-C_{q}^{i}\left(q_{i}\right)-t \delta_{i}+s, i=h, f
$$

Comparative static analysis is following:

$$
\begin{aligned}
& \frac{\partial q_{h}}{\partial t}=\frac{\delta_{h}\left(2 P^{\prime}+P^{\prime \prime} q_{f}\right)-\delta_{f}\left(P^{\prime}+P^{\prime \prime} q_{h}\right)}{A} \\
& \frac{\partial q_{f}}{\partial t}=\frac{\delta_{f}\left(2 P^{\prime}+P^{\prime \prime} q_{h}\right)-\delta_{h}\left(P^{\prime}+P^{\prime \prime} q_{f}\right)}{A} \\
& \frac{\partial Q}{\partial t}=\frac{\partial q_{h}}{\partial t}+\frac{\partial q_{f}}{\partial t}=\frac{\left(\delta_{h}+\delta_{f}\right) P^{\prime}(Q)}{A}<0 \\
& \frac{\partial q_{h}}{\partial s}=\frac{-\left(P^{\prime}+P^{\prime \prime} q_{f}-P^{\prime \prime} q_{h}\right)}{A} \\
& \frac{\partial q_{f}}{\partial s}=\frac{-\left(P^{\prime}+P^{\prime \prime} q_{h}-P^{\prime \prime} q_{f}\right)}{A} \\
& \frac{\partial Q}{\partial s}=\frac{\partial q_{f}}{\partial s}+\frac{\partial q_{h}}{\partial s}=\frac{-2 P^{\prime}(Q)}{A}>0
\end{aligned}
$$

By (32)-(37), etc., the increases of pollution emissions tax rate on the impact of individual manufacturers is not sure, but cannot rise at the same time, because of the increase of pollution emissions tax rate will reduce the overall market for renewable energy production; The impact on the individual manufacturer, meanwhile, by the subsidy rate increase is not sure, but it can't fall at the same time, because the rising tax rate would increase the total renewable energy production.

\subsubsection{Seeking the optimal renewable energy policy of the two governments after that}

The two governments formulate renewable energy policy jointly express the two countries to pursue joint benefits maximization, that is:

$$
W_{h}+W_{f}=W=\int_{0}^{Q} P(z) d z-\sum_{i=h, f} C^{i}\left(q_{i}\right)+B(Q)-D(E)
$$

To do the full differential of the United Social Welfare function for the pollution emission tax rate and net renewable energy subsidies of the maximum of the social welfare:

$$
\begin{aligned}
& \frac{\partial W}{\partial t}=\sum_{i}\left[P(Q)-C_{q}^{i}\left(q_{i}\right)+B^{\prime}(Q)-\delta_{i} D^{\prime}(E)\right] \frac{\partial q_{i}}{\partial t}=0 \\
& \frac{\partial W}{\partial s}=\sum_{i}\left[P(Q)-C_{q}^{i}\left(q_{i}\right)+B^{\prime}(Q)-\delta_{i} D^{\prime}(E)\right] \frac{\partial q_{i}}{\partial s}=0
\end{aligned}
$$

let:

$$
P(Q)-C_{q_{i}}^{i}\left(q_{i}\right)+B^{\prime}(Q)-\delta_{i} D^{\prime}(E)=0
$$

The formula (31) of first order condition of the manufacturer's profit is brought into formula (41):

$$
P^{\prime}(Q) q_{i}-t \delta_{i}+s-B^{\prime}(Q)+\delta_{i} D^{\prime}(E)=0
$$

Make the combined pollution emission tax rate and the optimal net joint renewable energy subsidies to:

$$
\begin{aligned}
& t=D^{\prime}(E) \\
& s=-\frac{Q}{2} P^{\prime}(Q)+B^{\prime}(Q)>B^{\prime}(Q)
\end{aligned}
$$

By formula (43) and formula (44), we know that the two governments formulate the optimal pollution emissions tax rate jointly between the two countries should be equal to the manufacturer's marginal damage. The optimal rate of clean renewable energy subsidies will be greater than the marginal benefit of renewable energy production, this is mainly the two manufacturers are exclusive manufacturers, production of its profit maximization will deviate from the optimal social production, therefore, to promote renewable energy production, the two government shall formulate rate higher than the marginal benefit subsidies of renewable energy. At the same time, compare formula (29) and formula (44), as you can see that if renewable energy production unchanged, the subsidy rate under cooperation between the two countries is lower than foreign government subsidy rate under not cooperation. Integrated formula (43) and formula (44), it can get the following proposition 2 .

Proposition 2: when the manufacturer does not have pollution prevention technology, if the two governments cooperative, they formulate optimal renewable energy policy jointly to levy is equal to Pigou tax of the marginal 
pollution damage; The subsidies of renewable energy rate of two governments is higher than the marginal revenue of renewable energy, but lower than subsidy rate on renewable energy of foreign governments when no cooperative.

4. Model solving (Ii): Manufacturers with pollution control technology

\subsection{If the two governments do not cooperate}

4.1.1. Seeking the manufacturer's optimal decision of the second stage firstly

Make the first order partial derivative of the formula (6) and the formula (7) what are profit function of the manufacturers in two countries equal to zero, there are:

$$
\begin{aligned}
& \frac{\partial \pi_{h}}{\partial q_{h}}=P(Q)+P^{\prime}(Q) q_{h}-C_{q}^{h}\left(q_{h}, e_{h}\right)=0 \\
& \frac{\partial \pi_{h}}{\partial e_{h}}=-C_{e}^{h}\left(q_{h}, e_{h}\right)-t_{h}=0 \\
& \frac{\partial \pi_{f}}{\partial q_{f}}=P(Q)+P^{\prime}(Q) q_{f}-\partial C^{f}\left(q_{f}, e_{f}\right) / \partial q_{f}+s=0 \\
& \frac{\partial \pi_{f}}{\partial e_{f}}=-\partial C^{f}\left(q_{f}, e_{f}\right) / \partial e_{f}-t_{f}=0
\end{aligned}
$$

After finishing, there are:

$$
\begin{aligned}
& P(Q)+P^{\prime}(Q) q_{h}=C_{q}^{h}\left(q_{h}, e_{h}\right) \\
& t_{h}=-C_{e}^{h}\left(q_{h}, e_{h}\right) \\
& P(Q)+P^{\prime}(Q) q_{f}+s=C_{q}^{f}\left(q_{f}, e_{f}\right) \\
& t_{f}=-C_{e}^{f}\left(q_{f}, e_{f}\right)
\end{aligned}
$$

We can know that the renewable energy production of manufacturers is impacted by the price which consumers are willing to pay, the manufacturer's production costs, renewable energy's the rate subsidies and the market demand elasticity that the manufacturers face; Pollution control quantity of manufacturers is impacted by their own pollution control costs and the rate of pollution emissions. In the case of the country, production marginal revenue of domestic manufacturers is equal to the production level of marginal cost, the manufacturers implement pollution prevention and control when the marginal cost of pollution prevention and control is equal to pollution discharge rate; The production quantity of foreign manufacturers will meet requirements when the result of marginal revenue and the net rate of renewable energy subsidies is equal to the marginal production cost, and the amount of pollution control will meet requirements when the marginal pollution control cost is equal to the pollution discharge rate.

Conducting comparative static analysis next:

$$
\frac{\partial q_{h}}{\partial t_{h}}=\frac{\partial q_{f}}{\partial t_{h}}=\frac{\partial e_{f}}{\partial t_{h}}=\frac{\partial q_{h}}{\partial t_{f}}=\frac{\partial q_{f}}{\partial t_{f}}=\frac{\partial e_{h}}{\partial t_{f}}=\frac{\partial e_{h}}{\partial s}=\frac{\partial e_{f}}{\partial s}=0
$$

$$
\begin{aligned}
& \frac{\partial e_{h}}{\partial t_{h}}=\frac{1}{-C_{e e}^{h}}<0 \\
& \frac{\partial e_{f}}{\partial t_{f}}=\frac{1}{-C_{e e}^{f}}<0 \\
& \frac{\partial q_{h}}{\partial s}=\frac{\left(P^{\prime}+P^{\prime \prime} q_{h}\right)}{A}<0 \\
& \frac{\partial q_{f}}{\partial s}=\frac{-\left(2 P^{\prime}+P^{\prime \prime} q_{h}\right)}{A}>0
\end{aligned}
$$

From the upper formulas (53)-(57), it can be seen that the pollution discharge tax rate has no effect on the renewable energy production of domestic manufacturers and foreign manufacturers, and has no effect on the pollution emissions of the competing countries' manufacturers, but will reduce the country's pollution emissions. Subsidies for renewable energy do not affect the optimal pollution emissions between the two countries' manufacturers but will impact renewable energy production of the two countries' manufacturer.

\subsubsection{Seeking the optimal renewable energy policy of the two governments after that}

First, seek the government's renewable energy policy, and then seek the first derivative of the emission tax rate using the domestic social welfare function:

$$
\begin{aligned}
& \frac{\partial W_{h}}{\partial t_{h}}=\left[P(Q)+P^{\prime}(Q) q_{h}-C_{q}^{h}\left(q_{h}, e_{h}\right)\right] \frac{d q_{h}}{d t_{h}}+P^{\prime}(Q) q_{h} \frac{d q_{f}}{d t_{h}} \\
& +\left[-C_{e}^{h}\left(q_{h}, e_{h}\right)-D^{\prime}\left(e_{h}\right)\right] \frac{d e_{h}}{d t_{h}}=0
\end{aligned}
$$

And thus:

$$
\left[-C_{e}^{h}\left(q_{h}, e_{h}\right)-D^{\prime}\left(e_{h}\right)\right] \frac{d e_{h}}{d t_{h}}=0
$$

By $-C_{e}^{h}-t_{h}=0$, it can be calculated:

$$
t_{h}=D^{\prime}\left(e_{h}\right)
$$

That the two countries do not cooperate, the optimal pollution tax rate of domestic government is equal to the marginal pollution damage, which is, the optimal pollution discharge rate is Pigou tax. In the same way, the optimal renewable energy subsidy rate and pollution emission rate of foreign governments can be obtained.

$$
\begin{aligned}
& \frac{\partial W_{f}}{\partial t_{f}}=\left[P(Q)-P^{\prime}(Q) q_{h}-C_{q}^{f}\left(q_{f}, e_{f}\right)+B^{\prime}(Q)\right] \frac{\partial q_{f}}{\partial t_{f}}+ \\
& {\left[B^{\prime}(Q)-P^{\prime}(Q) q_{h}\right] \frac{\partial q_{h}}{\partial t_{f}}+\left[-C_{e}^{f}-D^{\prime}\left(e_{f}\right)\right] \frac{\partial e_{f}}{\partial t_{f}}=0} \\
& \frac{\partial W_{f}}{\partial s}=\left[P(Q)-P^{\prime}(Q) q_{h}-C_{q}^{f}\left(q_{f}, e_{f}\right)+B^{\prime}(Q)\right] \frac{\partial q_{f}}{\partial s} \\
& +\left[B^{\prime}(Q)-P^{\prime}(Q) q_{h}\right] \frac{\partial q_{h}}{\partial s}+\left[-C_{e}^{f}-D^{\prime}\left(e_{f}\right)\right] \frac{\partial e_{f}}{\partial s}=0
\end{aligned}
$$

By formulas (53), (55), (61), there is:

$$
-C_{e}^{f}\left(q_{f}, e_{f}\right)-D^{\prime}\left(e_{f}\right)=0
$$


In combination with $-C_{e_{f}}^{f}-t_{f}=0$, there is:

$$
t_{f}=D^{\prime}\left(e_{f}\right)
$$

In combination with formulas (51), (56), (57), there is:

$$
s=B^{\prime}(Q)-P^{\prime}(Q) Q+\left[B^{\prime}-P^{\prime}(Q) q_{h}\right] \frac{P^{\prime}+P^{\prime \prime} q_{h}}{2 P^{\prime}+P^{\prime \prime} q_{h}}
$$

From the formulas (54), it can be seen that foreign government's best pollution discharge rate is equal to the marginal pollution damage, that is, the optimal pollution discharge rate is Pigou tax. Secondly, from the formulas (65), it can be seen that the optimal renewable energy subsidy rate of the foreign government is greater than the marginal revenue of renewable energy. For the reasons, see the description of formulas (29) above.

Proposition 3: when manufacturers have pollution prevention technology, if the governments of the two countries don't cooperate and its optimal renewable energy policy to levy is equal to the marginal pollution damage of Pigou tax; Foreign government's pollution emission tax rate is equal to the marginal pollution damage, its subsidy rate is higher than the marginal revenue of the renewable energy.

\subsection{If the two governments cooperate}

\subsubsection{Seeking the manufacturer's optimal decision of the second stage firstly}

If the two governments develop renewable energy policies jointly, they will determine the tax rate of pollution emissions and renewable energy subsidies to pursue joint social welfare maximization. At this time, the profit function of two countries' manufacturers is the following:

$$
\pi_{i}=P(Q) q_{i}-C^{i}\left(q_{i}, e_{i}\right)-t e_{i}+s q_{i}
$$

The first-order conditions of Profit maximization are:

$$
\begin{aligned}
& \frac{\partial \pi_{i}}{\partial q_{i}}=P(Q)+P^{\prime}(Q) q_{i}-C_{q}^{i}\left(q_{i}, e_{i}\right)+s=0 \\
& \frac{\partial \pi_{i}}{\partial e_{i}}=-C_{e}^{i}\left(q_{i}, e_{i}\right)-t=0
\end{aligned}
$$

It can get comparative static derivatives as follows through calculation:

$$
\begin{aligned}
& \frac{\partial q_{h}}{\partial t}=\frac{\partial q_{f}}{\partial t}=\frac{\partial e_{h}}{\partial s}=\frac{\partial e_{f}}{\partial s}=0 \\
& \frac{\partial e_{h}}{\partial t}=-\frac{1}{C_{e e}^{h}}<0 \\
& \frac{\partial e_{f}}{\partial t}=-\frac{1}{C_{e e}^{f}}<0 \\
& \frac{\partial E}{\partial t}=-\left(\frac{1}{C_{e e}^{h}}+\frac{1}{C_{e e}^{f}}\right)<0 \\
& \frac{\partial q_{h}}{\partial s}=\frac{-\left(P^{\prime}+P^{\prime \prime} q_{f}-P^{\prime \prime} q_{h}\right)}{A}
\end{aligned}
$$

$$
\begin{aligned}
& \frac{\partial q_{f}}{\partial s}=-\frac{\left(P^{\prime}+P^{\prime \prime} q_{h}-P^{\prime \prime} q_{f}\right)}{A} \\
& \frac{\partial Q}{\partial s}=\frac{\partial q_{h}}{\partial s}+\frac{\partial q_{f}}{\partial s}=\frac{-2 P^{\prime}(Q)}{A}>0
\end{aligned}
$$

The formulas (69)- express that the combined pollution discharge rate of two governments have no effect on renewable energy production in the two countries, but will inhibition of the company's pollution emissions; The combined rate of renewable energy subsidies will not affect the level of pollution emissions between the two countries' manufacturers, but will increase the renewable energy production of overall market.

\subsubsection{Seeking the optimal renewable energy policy of the two governments after that}

The social welfare function under the two governments' cooperation can be expressed as follows:

$$
W_{h}+W_{f}=W=\int_{0}^{Q} P(z) d z-\sum_{i=h, f} C^{i}\left(q_{i}, e_{i}\right)+B(Q)-D(E)
$$

The first order partial derivative of the union social welfare:

$$
\begin{aligned}
& \frac{\partial W}{\partial t}=\sum_{i}\left[P(Q)-C_{q}^{i}\left(q_{i}, e_{i}\right)+B^{\prime}(Q)\right] \frac{\partial q_{i}}{\partial t} \\
& +\sum_{i}\left[-C_{e}^{i}\left(q_{i}, e_{i}\right)-D^{\prime}(E)\right] \frac{\partial e_{i}}{\partial t}=0 \\
& \frac{\partial W}{\partial s}=\sum_{i}\left[P(Q)-C_{q}^{i}\left(q_{i}, e_{i}\right)+B^{\prime}(Q)\right] \frac{\partial q_{i}}{\partial s} \\
& +\sum_{i}\left[-C_{e}^{i}\left(q_{i}, e_{i}\right)-D^{\prime}(E)\right] \frac{\partial e_{i}}{\partial s}=0
\end{aligned}
$$

Combined with the above formulas and formulas (69)-(74), it can get the followings:

$$
-C_{e}^{i}-D^{\prime}(E)=0
$$

Bring formulas (67), (68) into formulas (77), (78), (79), there are:

$$
\begin{aligned}
& t=D^{\prime}(E) \\
& s=B^{\prime}(Q)-\frac{Q}{2}\left[P^{\prime}(Q)\right]-\frac{1}{2} P^{\prime \prime} Q^{2}
\end{aligned}
$$

It can know from the above two formulas that the two governments formulate the optimal discharge rate jointly is equal to the marginal damage of the total pollution of the two countries. The optimal renewable energy subsidy rate is greater than the marginal revenue of renewable energy. The reason lies in: the two manufacturers are exclusive manufacturers, so they will deviate from the social optimum when pursuit of their own profit maximization. To promote the production of renewable energy, the two governments will develop a higher subsidy rate than marginal revenue of renewable energy. So it may have the following proposition:

Proposition 4: If the two governments cooperate, the joint pollution discharge rate is equal to the marginal damage of total pollution of the two countries when the manufacturer has pollution prevention technology; the combined 
renewable energy subsidy rate is greater than the marginal revenue of renewable energy.

\section{Research conclusions and policy implications}

Renewable energy industry has positive and negative externalities: the production process needs to consume fossil energy which brings negative externalities, while the use of fossil energy can reduce environmental pollution, and it has positive externalities. In international trade, if the country's renewable energy products are exported to foreign countries and compete with foreign manufacturer $s$ in foreign countries, how should the optimal policy of the two countries be? We establish a dynamic game model of the two manufacturers of the two countries, which is based on the assumption that manufacturers are going to Cournot quantity competition, and the optimal tax rate and subsidy policies of the two countries are studied under the assumption that the firm's profit is maximized and the government's social welfare is maximized. The followings are the conclusion of this paper.

\subsection{If the two governments cooperate}

1. Regardless of the pollution prevention and control technology in the market, the joint pollution discharge tax rate is always equal to the marginal damage of the total pollution emissions; the combined renewable energy subsidy rate is higher than the marginal revenue of the total output of renewable energy.

2. In general, the environmental policy of renewable energy exporting countries is tax; and the tax rate decreases with the market forces increases in domestic manufacturers. Its domestic manufacturers will be taxed on the pollution emissions, but will to subsidize for them in the foreign country which is the renewable energy consumption country, and the lower the output of foreign manufacturers, the higher the subsidy rate.

\subsection{If the two governments do not cooperate}

The national pollution discharge rate and the level of foreign subsidies will be set according to whether the two manufacturers with pollution control technology.

1. When the two companies have no pollution control technology, pollution emission rates of domestic manufacturers is lower than their marginal damage of pollution, rate of foreign subsidies is higher. The reason may be that the output of domestic manufacturers is improved by the lower tax rate of the government. To improve the market competitiveness of foreign manufacturers, foreign governments will adopt a higher subsidy rate.

2. On the contrary, pollution tax rate's improvement of domestic manufacturers (tax rate is equal to the pollution of the marginal damage) will reduce domestic production when the manufacturers of the two countries have pollution control technology, and decreases foreign manufacturers competitive pressure, so foreign government subsidy rate will be decreased.
The conclusion of the above analysis has very policy implications:

First, if the renewable energy policy cooperation between countries is difficult to achieve at present and the government is renewable energy exporting countries in reality, such as China, the government should impose pollution emissions tax to improve the level of the domestic welfare when the facing situation in the country is similar to this situation. And if the country which faces the situation is foreign countries in the text, then we should take two policies to its domestic renewable energy production: on the one hand to subsidize, on the other hand, it should be levied pollution emissions tax. Of course, if the two governments' cooperation is easy to achieve, then the optimal renewable energy policy of the two countries' manufacturers should both subsidies and tax to improve the welfare level of the two countries.

Second, whether the government cooperate or don't, with the situation that the pollution prevention and control technology's improvement of manufacturers and other conditions such as total output of renewable energy is equality is the same, and due to the decline in pollution emissions, the optimal tax rate of pollution and the rate of subsidies of government should be reduced.

\section{References}

Amina A. and Kamel K. (2019), Water quality of the Kebir watershed, Northeast of Algeria, Journal Clean Was, 3(1), 2832.

Barnett A.H. (1980), The Pigouvian tax rule under monopoly, American Economic Review, 70, 1037-1041.

Barrett S. (1994), Strategic environmental policy and international trade, Journal of Public Economics, 54, 325-338.

Baumol W.J. and Oates W.E. (1988), The Theory of Environmental Policy, 4th edition, Cambridge University Press, Cambridge.

Bernhofen D.M. (1997), Strategic trade policy in a vertically related industry, Review of International Economics, 5, 429-433.

Brander J. and Spencer B. (1985), Export subsidies and market share rivalry, Journal of International Economics, 18, 83-100.

Buchanan J.M. (1969), External diseconomies, corrective taxes, and market structure, American Economic Review, 59, 174-177.

Conrad K. (1993), Taxes and subsides for pollution-industries as trade policy, Journal of Environmental Economics and Management, 25, 121-135.

Copeland B.R. (1994), International trade and the environment: policy reform in a polluted small open economy, Journal of Environmental Economics and Management, 26, 44-65.

Dali N.M. and Kamarudin K.S.N. (2018), The Effect of Cosurfactant In $\mathrm{CO}_{2}$ Absorption in Water - In - Oil Emulsion, Environment \& Ecosystem Science, 2(2), 42-46.

Dijkstra B.R., Mathew A.J. and Mukherjee A. (2011), Environmental regulation: an incentive for foreign direct investment, Review of International Economics, 19, 568-578.

Dong B., Gong J. and Zhao X. (2012), FDI and environmental regulation: pollution haven or a race to the top? Journal of Regulatory Economics, 41, 216-237. 
Eaton J and Grossman G.M. (1986) Optimal trade and industrial policy under oligopoly. The Quarterly Journal of Economics, 101, 383-406.

Farzin Y.H. (2003), The effects of emissions standards on industry, Journal of Regulatory Economics, 24, 315-327.

https://www.econstor.eu/dspace/bitstream/10419/22000/1/EW P-2005-12.pdf.

Ibrahim S., Razak Z., Rosnan Y., Md. S.I. and Nasir M.I. (2018), SWAT Subbasins Parameters and Flood Risk Simulations Using 3d In Terengganu Watershed, Earth Sciences Malaysia, 2(2), 10-15.

Ishikawa J. and Spencer B.J. (1999), Rent-shifting export subsidies with an imported intermediate product, Journal of International Economics, 48(2), 199-232.

Misiolek W.S. (1988) Pollution control through price incentives: the role of rent seeking costs in monopoly markets, Journal of Environmental Economics and Management, 15, 1-8.

Most. N.S., Md Sahadat H. and Gulshan A.L. (2019), Water quality assessment of Balu River, Dhaka Bangladesh, Water Conservation and Management, 3(1), 08-10.

Mozina A., Kaniz F., Palwasha K., Ejaz U.H., Azhar A., Samiullah D., Ahthasham S and Muhammad Z. (2018), Internet of things its environmental applications and challenges, Environmental Contaminants Reviews, 1(2), 01-03.

Muhammad F.L., Muhammad Y.K., Taj M.J.K., Abdul H.L., Muhammad S.J., Abdul H.K., Imran K.R., Aftab H.K. and Jagirani M.D. (2020) Risk assessment of heavy metals and salts for human and irrigation consumption of groundwater in Qambar city: a case study, Geology, Ecology, and Landscapes, 4(1), 23-39.

Nur A.A. and Zarina Z. (2020), Tissue Culture of ficus Carica variety Btm-6, Malaysian Journal of Sustainable Agriculture, 4(1), 26-28.

Pigou A. (1932), The Economics of Welfare, 4th edition, Macmillan, London.

Requate T. (2005), Environmental Policy under Imperfect Competition: A Survey [EB/OL], Economics Working Papers, 12.

Smith V.X. (1976), A note on effluent charges and market structure, Journal of Environmental Economics and Management, 2: 309-311.

Ulph A. (1996), Environmental policy instrument and imperfect competitive international trade, Environmental and Resource Economics, 7: 333-355.

Ulph A. (1997), International trade and the environment: a survey of recent economic analysis. The international yearbook of environmental and resource economics 1997/1998: a survey of current issues, 205-243.

Yang B.Y. and Xu S.Y. (2015) Environment policy under the open economy: trans-boundary pollution and regional pollution, Journal of Dongwu Business Economics, 88, 45-72.

Yasin R., M. Sabir K. and Saleem M. (2018), Petrography of Sandstone of The Lumshiwal Formation from Eastern Hazara, Khyber Pakhtunkhwa, Pakistan: Implications For Provenance, Diagenesis And Environments Of Deposition, Earth Sciences Pakistan, 2(2), 01-06. 